\title{
Uso da metodologia de coleta total de excretas na determinação da energia metabolizável em rações para frangos de corte ajustadas ou não quanto aos níveis de vitaminas e minerais ${ }^{1}$
}

\author{
Valdir Silveira de Avila², Aline Paula ${ }^{3}$, Paulo Antônio Rabenschlag de Brum ${ }^{4}$, Waldomiro \\ Barioni Júnior ${ }^{5}$, João Carlos Maier ${ }^{6}$
}

\footnotetext{
1 Parte da dissertação de Mestrado apresentada à UFPel pela segunda autora para obtenção do título de Mestre em Ciências.

2 EMBRAPA/CNPSA.

${ }^{3}$ Departamento de Estudos Agrários da Universidade Regional do Noroeste do Estado do Rio Grande do Sul.

${ }^{4}$ EMBRAPA/CNPSA. Bolsista do CNPq.

${ }^{5}$ Estatístico, EMBRAPA/CNPSA.

${ }^{6}$ DZ da UFPEL
}

RESUMO - Avaliou-se neste estudo a influência dos teores de vitaminas e microminerais da ração-teste na determinação dos valores de energia metabolizável aparente (EMA) e energia metabolizável aparente corrigida pelo nitrogênio retido (EMAn) do farelo de soja. Foram comparadas rações-teste ajustadas ou não para as quantidades de cloreto de colina e premix de vitaminas e microminerais em relação à ração-referência. Adotou-se o método tradicional de coleta total de excretas utilizando-se 360 pintos de corte machos e fêmeas da linhagem Ross de 15 a 23 dias de idade, alojados em baterias metálicas com bandejas coletoras de excretas. As aves foram distribuídas em esquema de blocos casualizados, de acordo com o andar das baterias, com dois tratamentos e 12 repetições de dez aves (cinco machos e cinco fêmeas). Em um tratamento, efetuou-se a substituição de $40 \%$ da ração-referência por farelo de soja, enquanto no outro, além dessa substituição, ajustaram-se as quantidades de cloreto de colina e dos premixes de vitaminas e microminerais com base na ração-referência. Os valores médios e os respectivos erros-padrão para EMA e EMAn (kcal/kg) do farelo de soja, com base na matéria natural, foram $2.462 \pm 29,62$ e $2.269 \pm 25,80$ para ração ajustada e $2.353 \pm 26,18$ e $2.191 \pm 23,88$ para ração não ajustada. $\mathrm{O}$ ajuste das quantidades de cloreto de colina e do premix de vitaminas e microminerais na ração-teste propiciou maiores valores de EMA e EMAn do farelo de soja em relação à ração não-ajustada. É importante ajustar as quantidades de vitaminas e microminerais nas rações-teste em experimentos visando determinar a energia metabolizável de ingredientes para aves.

Palavras-chave: aves, energia, métodos, micronutrientes, nutrição

\section{Adjustment of the total excreta collection method for metabolizable energy determination of broiler chicken fedstuffs: consideration of vitamin and micro-minerals levels in the test diet}

\begin{abstract}
The objective of this study was to evaluate the effects of vitamin and micromineral levels adjustment in the test diet on the total collection method for determination of apparent metabolizable energy (EMA) and apparent metabolizable energy corrected by nitrogen retention (EMAn) of soybean meal. Two treatments were compared: the test diet without or with adjustments in the amounts of choline chloride and vitamin-micromineral premix, when $40 \%$ of the reference diet was replaced with soybean meal. The traditional total feces collection method was used, with 360 Ross broilers from 15 to 23 days old. The chickens were allotted to batteries as a randomized block design, with two treatments and 12 ten-birds replicates (five males and five females). Mean values and respective standard errors for EMA and EMAn ( $\mathrm{kcal} / \mathrm{kg}$ ) of soybean meal, as-fed basis, were of 2,462 29.62 and $2,269 \pm 25.80$ for the adjusted diet and 2,353 \pm 26.18 and 2,191 \pm 23.88 for the diet without vitamin and micromineral adjustment. Adjustments of the amounts of choline choride and vitamin-micromineral premix in the test diet led to higher EMA and EMAn compared to the control test diet with no adjustments. Therefore, vitamin and micromineral levels in the test diet should be adjusted to the reference diet in experiments determining the metabolizable energy of feedstuffs used in poultry diets.
\end{abstract}

Key Words: chicken, energy, methods, micronutrients, nutrition

\section{Introdução}

A segunda metade do século XX caracterizou-se por uma enorme expansão da produção avícola. O aumento no volume e na eficiência de produção de aves pode ser atribuído ao desenvolvimento paralelo de novos conhecimentos em sanidade, ambiência, genética e nutrição. 
Conforme Uni et al. (1998), o progresso na nutrição de aves nos últimos 50 anos pode ser atribuído a diversos fatores, incluindo o uso de vitaminas sintéticas e enzimas, a adição de macro e micro elementos às dietas, a utilização de aminoácidos (incluindo proteína ideal) em vez de PB e a relação energia:proteína. Esses autores relatam ainda o desenvolvimento de um grande número de programas alimentares para satisfazer às exigências das diferentes linhas genéticas, o desenvolvimento genético dos grãos, o processamento e a avaliação da energia dos alimentos utilizando valores de energia metabolizável aparente e verdadeira.

Nos últimos 20 anos, têm sido realizadas poucas pesquisas sobre as exigências de vitaminas para frangos de corte. Na realidade, muitos dados utilizados atualmente na indústria foram desenvolvidos há muito tempo e a maioria pode estar desatualizada (por exemplo o NRC, 1994), considerando-se a mudança das exigências nutricionais com a evolução genética das aves, razão pela qual raramente essas exigências são utilizadas pelos nutricionistas.

As vitaminas são baratas em relação a outros nutrientes e, por isso, sua importância é geralmente relegada nas pesquisas nutricionais. Entretanto, as deficiências de vitaminas podem ocasionar efeitos profundos e duradouros no desempenho dos animais.

Teixeira et al. (1990) verificaram que a inclusão de 50\% a mais de vitaminas (menos colina) em uma ração controle suplementada com premix mineral e vitamínico melhorou o ganho de peso e a conversão alimentar de frangos de corte no período de 7 a 21 dias de idade, enquanto a inclusão de $50 \%$ de minerais extra (menos selênio) melhorou o desempenho somente no período de 21 a 35 dias de idade e não teve efeito no período inicial.

Por outro lado, Deyhim \& Teeter (1993) registraram que a retirada do suplemento vitamínico e mineral da ração no período de 28 a 49 dias de idade provocou redução do ganho de peso e da eficiência alimentar.

Skinner et al. (1992), ao retirarem a suplementação vitamínica e mineral das rações para as fases de crescimento e final, não observaram efeito adverso sobre o desempenho e a qualidade de carcaça em nenhum dos períodos estudados.

Existe uma variação considerável nos níveis recomendados, principalmente de vitaminas, e essa variação é muito superior à que ocorre com as recomendações para outros nutrientes, como aminoácidos. Parece improvável que existam diferenças tão grandes nas exigências desses nutrientes entre as linhagens.

Embora não tenham sido encontradas informações específicas sobre o efeito da suplementação de vitaminas e minerais nas dietas-teste, em estudos para determinar a EMA e EMAn pelo método de coleta total de excretas, espera-se algum efeito sobre a digestibilidade da energia quando há deficiência desses nutrientes. Desta forma, realizou-se este trabalho com o objetivo de determinar os valores de EMA e EMAn do farelo de soja utilizando-se rações-teste para aves, corrigidas ou não quanto aos níveis de cloreto de colina e de premixes vitamínico e micromineral.

\section{Material e Métodos}

Este trabalho foi realizado nas dependências da Embrapa Suínos e Aves (CNPSA), localizada no município de Concórdia-SC.

Foram utilizados 360 pintos de corte da linhagem Ross criados em baterias com aquecimento elétrico no período de 1 a 14 dias de idade. A partir desta idade, as aves foram separadas por sexo e distribuídas ao acaso em boxes (cinco machos e cinco fêmeas, por repetição), sendo submetidas à temperatura controlada de $24^{\circ} \mathrm{C}$, que fica na faixa de conforto dos animais. A partir desse período, as aves receberam uma ração-referência com $21 \%$ de $\mathrm{PB}$ e $3.000 \mathrm{kcal}$ de EM/kg. Durante todo o período experimental, as aves foram mantidas em regime de luz natural, com rações e água à vontade, fornecidas em comedouros e bebedouros tipo calha.

Foram comparados dois métodos para determinação da energia metabolizável: tratamento 1 - $40 \%$ de substituição da ração-referência por farelo de soja, de acordo com a metodologia tradicional de coleta total de excretas, conforme Hill \& Anderson (1958); tratamento 2 - 40\% de substituição da ração-referência por farelo de soja, semelhantemente ao tratamento 1, porém corrigindo-se as quantidades de cloreto de colina e dos premixes vitamínico e micromineral em relação à ração-referência. É importante ressaltar que a quantidade de sal (cloreto de sódio) no tratamento 2 não foi corrigida e que, ao corrigir o tratamento 2 , as quantidades de cloreto de colina dos premixes vitamínico e micromineral resultaram em acréscimo de $0,11 \%$ no total da ração (Tabela 1 ). Entretanto, considerou-se este acréscimo desprezível.

A mistura dos ingredientes da ração-referência foi feita em misturador vertical com capacidade para $500 \mathrm{~kg}$ durante 15 minutos. A mistura das rações-teste foi realizada em misturador Y com capacidade para $90 \mathrm{~kg}$ durante 10 minutos. As rações foram acondicionadas em sacos plásticos e estocadas no local do experimento. As composições das duas rações experimentais e da ração-referência são apresentadas na Tabela 1.

A ração-teste foi fornecida à vontade, durante nove dias (15 a 23 dias de idade), sendo quatro dias para adaptação das 
Tabela 1 - Composição das rações experimentais

Table 1 - Composition of the reference and test diets

\begin{tabular}{|c|c|c|c|}
\hline \multirow[t]{2}{*}{$\begin{array}{l}\text { Ingrediente }(\%) \\
\text { Ingredient }(\%)\end{array}$} & \multicolumn{3}{|c|}{$\begin{array}{c}\text { Quantidade }(\mathrm{kg}) \\
\text { Amount }(\mathrm{kg})\end{array}$} \\
\hline & Ração-referência (Control) & $\mathrm{T} 1$ & T 2 \\
\hline Farelo de soja $44,84 \%$ (Soybean meal $44.84 \%$ ) & 35,96 & 21,57 & 21,57 \\
\hline Fosfato bicálcico (Dicalcium phosphate) & 1,80 & 1,08 & 1,08 \\
\hline DL-metionina (DL-methionine) & 0,42 & 0,26 & 0,26 \\
\hline Sal (Salt) & 0,41 & 0,25 & 0,25 \\
\hline В H T & 0,005 & 0,003 & 0,003 \\
\hline Premix vitamínico (Vitamin premix) & $0,10^{1}$ & 0,06 & $0,06+0,04$ \\
\hline Premix micromineral (Micro-mineral) & $0,10^{2}$ & 0,06 & $0,06+0,04$ \\
\hline Tylan 40 & 0,005 & 0,003 & 0,003 \\
\hline Cloreto de colina $(70 \%)$ (Choline chloride) & 0,074 & 0,044 & $0,044+0,030$ \\
\hline Proteína bruta (\%) (Crude protein) & 21 & 31 & 31 \\
\hline Energia metabolizável ( $\mathrm{kcal} / \mathrm{kg}$ ) (Metabolizable energy) & 3.000 & 2.796 & 2.796 \\
\hline Cálcio (\%) (Calcium) & 0,96 & 0,69 & 0,69 \\
\hline Fósforo disponível (\%) (Available phosphorus) & 0,46 & 0,36 & 0,36 \\
\hline Metionina (\%) (Methionine) & 0,75 & 0,71 & 0,71 \\
\hline Metionina + cistina $(\%)$ (Methionine + cystine $)$ & 1,11 & 1,19 & 1,19 \\
\hline Lisina $(\%)$ (Lysine) & 1,20 & 1,90 & 1,90 \\
\hline
\end{tabular}

aves às novas rações e cinco para coleta total de excretas em cada unidade experimental. Aos 19 dias de idade, após a devida adaptação das aves às rações, iniciou-se o período de coleta de excretas. As rações foram pesadas no início do experimento e as sobras no final do período de coleta, para determinação dos consumos alimentar e de energia bruta.

As coletas de excretas foram realizadas diariamente, em intervalos de 24 horas, durante os cinco dias. As bandejas foram cobertas com plástico e colocadas sob cada boxe da bateria, de modo a individualizar o material e evitar perdas, para que todas as excretas da unidade experimental pudessem ser coletadas.

As excretas recolhidas em cada unidade experimental, após eliminação de penas, resíduos de ração e outras fontes de contaminação, foram transferidas para sacos plásticos identificados, sendo pesadas e armazenadas em congelador até o final do período de coleta. Posteriormente, as amostras foram descongeladas, reunidas por repetição e homogeneizadas, retirando-se alíquotas de 400 a $500 \mathrm{~g}$, que foram mantidas em estufas ventiladas, a $55^{\circ} \mathrm{C}$, durante 48 horas, para secagem e posterior análise (Mazzuco et al.,
2002) no Laboratório Físico-Químico da Embrapa Suínos e Aves.

Os valores de MS e nitrogênio nas excretas e rações e de MS nos ingredientes foram determinados de acordo com a AOAC (1995). Os valores de EB das rações e das excretas foram determinados por meio de bomba calorimétrica pelo método descrito por Parr Instruments Co. (1984).

Para determinação da EMAn, foi utilizado o método de coleta total de excretas, de Hill \& Anderson (1958), descrito por Mazzuco et al. (2002). Os valores de EM do farelo de soja foram calculados e ajustados com base na retenção de nitrogênio utilizando-se a fórmula de Matterson et al. (1965).

$\mathrm{O}$ delineamento experimental foi composto de dois tratamentos com 12 repetições, em blocos casualizados, conforme o andar da bateria. Além dos tratamentos experimentais, para os cálculos dos valores de EMA e EMAn, foram utilizadas 12 repetições da ração-referência, de acordo com a metodologia de coleta total de excretas. Os dados foram analisados por meio de análise de variância, pelo procedimento GLM do SAS (2001), e as médias entre os tratamentos comparadas pelo teste t a 5\% de significância. 


\section{Resultados e Discussão}

Houve diferença significativa $(\mathrm{P}<0,05)$ nos valores estimados de EMA e EMAn, que foram superiores para a ração com correção da quantidade de cloreto de colina e dos premixes vitamínico e micromineral, em comparação àquela sem correção (Tabela 2). Esse resultado provavelmente foi ocasionado pelo maior desbalanceamento em vitaminas e microminerais, que determinou menor absorção e metabolismo de carboidratos e lipídios e, conseqüentemente, gerou menores valores de EM.

Não foram encontrados na literatura trabalhos sobre a determinação da EM de ingredientes nas rações-teste. Entretanto, Coelho (1983) afirma que, de modo geral, os valores de EM dos ingredientes utilizados na alimentação de aves são influenciados por fatores como deficiências múltiplas de aminoácidos e vitaminas, níveis de cálcio e fósforo, nível de inclusão do ingrediente-teste, entre outros, o que está de acordo com o observado neste trabalho, no qual houve efeito da suplementação de vitaminas sobre os valores de EMA e EMAn.

Embora não tenham estudado especificamente os efeitos na digestibilidade da energia, Teixeira et al. (1990) verificaram que a inclusão de vitaminas em níveis acima do recomendado melhorou o ganho de peso e a conversão alimentar de frangos de corte no período de 7 a 21 dias de idade. Deyhim \& Teeter (1993), no entanto, observaram que a retirada dos suplementos vitamínico e mineral da ração durante o período de 28 a 49 dias de idade provocou redução do ganho de peso e da eficiência alimentar.

Tabela 2 - Valores médios de EMA e EMAn do farelo de soja, com respectivos erros-padrão da média e coeficientes de variação

Table 2 - Mean values of AME and AMEn of soybean meal and the respective standard errors and coefficients of variation

\begin{tabular}{lcc}
\hline Variável & \multicolumn{2}{c}{$\begin{array}{c}\text { Dieta-teste } \\
\text { Contrable }\end{array}$} \\
\cline { 2 - 3 } & $\begin{array}{c}\text { Sem ajuste } \\
\text { Without adjustment }\end{array}$ & $\begin{array}{c}\text { Com ajuste* } \\
\text { With adjustment }\end{array}$ \\
\hline EMA & $2.353 \mathrm{~b} \pm 26,18$ & $2.462 \mathrm{a} \pm 29,62$ \\
CV $(\%)$ & 3,34 & 3,61 \\
EMAn & $2.191 \mathrm{~b} \pm 23,88$ & $2.269 \mathrm{a} \pm 25,80$ \\
CV $(\%)$ & 3,27 & 3,41 \\
\hline
\end{tabular}

* Ração-teste com níveis de vitaminas e microminerais ajustados em relação à ração-referência.

Letras distintas na mesma linha diferem significativamente entre si $(\mathrm{P}<0,05)$ pelo teste $\mathrm{t}$.

* Control diet with levels of vitamins and micro-minerals adjusted in relation to the reference diet.

Means with different letters in the same row differ significantly at $P<0.05$ ( $t$ test).
A literatura mencionada nesse trabalho demonstra que a suplementação vitamínica e mineral altera o desempenho dos frangos de corte e, conforme sugerido, embora sejam raros os dados que confirmem esta hipótese, acredita-se nesta influência da suplementação sobre os valores de EMA e EMAn.

\section{Conclusões}

A correção das quantidades de cloreto de colina e dos premixes vitamínico e micromineral na ração-teste, equiparando-se à ração-referência, resultou em maiores valores de EMA e EMAn do farelo de soja, quando comparados aos valores determinados com uso da ração sem correção.

É importante a correção das quantidades de cloreto de colina e dos premixes vitamínico e micromineral nas raçõesteste em experimentos para determinação da energia metabolizável de ingredientes para aves. No entanto, mais experimentos devem ser desenvolvidos, inclusive com outros ingredientes, para confirmar os resultados obtidos neste estudo.

\section{Literatura Citada}

ASSOCIATION OF OFFICIAL ANALITICAL CHEMISTS - AOAC. Official methods of analysis. 16.ed. Washington, D.C.: 1995. $1094 \mathrm{p}$.

COELHO, M.G.R. Valores energéticos e de triptofano metabolizável de alimentos para aves, utilizando duas metodologias. Viçosa, MG: Universidade Federal de Viçosa, 1983. 77p. Dissertação (Mestrado em Zootecnia) - Universidade Federal de Viçosa.

DEYHIM, F.; TEETER, R.G. Dietary vitamin and/or trace mineral premix effects on performance, humoral mediated immunity, and carcass composition of broilers during thermoneutral and high ambient temperature distress. Journal of Applied Poultry Research, v.2, p.347-355, 1993.

HILL, F.W.; ANDERSON, D.L. Comparation of metabolizable energy and productive energy determination with growing chicks. Poultry Science, v.64, p.587-603, 1958.

MATTERSON, L.D.; POTTER, L.M.; STUTZ, M.W. The metabolizable energy of feed ingredients for chickens. University of Connecticut Agricultural Experiment Station. Research Report, v.7. p.3-11, 1965.

MAZZUCO, H.; LORINI, I.; BRUM, P.A.R. et al. Composição química e energética do milho com diversos níveis de unidade na colheita e diferentes temperaturas de secagem para franos de corte. Revista Brasileira de Zootecnia, v.31, n.6, p.22162220, 2002.

NATIONAL RESEARCH COUNCIL - NRC. Nutrient requeriments of poultry. Washington, D.C.: National Academy Press, 1994. $155 \mathrm{p}$.

PARR INSTRUMENTS CO. Instructions for the 1241 and 1242 adiabatic calorimeters. Moline: 1984. 29p. (Parr Manual, 153)

SKINNER, J.T.; WALDROUP, A.L.; WALDROUP, P.W. Effects of protein and amino acid level fed zero to forty-two days on response of broilers to protein and amino acid levels fed fortytwo to forty-nine days of age. Poultry Science, v.71, p.13641373, 1992. 
STATISTICAL ANALYSIS SYSTEM - SAS. System for Microsoft Windows: release 8.2. Cary: 2001. (CD-ROM)

TEIXEIRA, Z.S.; HOSSAIN, S.M.D.; PASSOS JR., H.S. et al. Efeitos dos níveis de vitaminas e minerais sobre o desempenho de frangos de corte. In: REUNIÃO ANUAL DA SOCIEDADE BRASILEIRA DE ZOOTECNIA, 27., 1990, Campinas. Anais... Campinas: Sociedade Brasileira de Zootecnia, 1990. p.139.
UNI, Z.; GANOT, S.; SKLAN, D. Posthaste development of mucosal functions in the broiler small intestine. Poultry Science, v.77, n.1, p.75-82, 1998 .

Recebido: 03/12/04 Aprovado: 03/03/06 